\title{
Overexpression of Neurotrophin-3 Stimulates a Second Wave of Dopaminergic Amacrine Cell Genesis after Birth in the Mouse Retina
}

\author{
Miho Yoshida, ${ }^{1 *}$ Liang Feng, ${ }^{1 *}$ François Grimbert, ${ }^{1}$ Krsna V. Rangarajan, ${ }^{1}$ William Buggele, ${ }^{1}$ David R. Copenhagen, ${ }^{2}$ \\ Jianhua Cang, ${ }^{1}$ and Xiaorong Liu ${ }^{1}$ \\ ${ }^{1}$ Department of Neurobiology and Physiology, Northwestern University, Evanston, Illinois 60208, and ${ }^{2}$ Department of Ophthalmology, University of \\ California, San Francisco, San Francisco, California 94143
}

\begin{abstract}
Dopaminergic amacrine (DA) cells play multiple and important roles in retinal function. Neurotrophins are known to modulate the number and morphology of DA cells, but the underlying regulatory mechanisms are unclear. Here, we investigate how neurotrophin-3 (NT-3) regulates DA cell density in the mouse retina. We demonstrate that overexpression of NT-3 upregulates DA cell number and leads to a consequent increase in the density of DA cell dendrites. To examine the mechanisms of DA cell density increase, we further investigate the effect of NT-3 overexpression on retinal apoptosis and mitosis during development. We find that NT-3 does not affect the well known wave of retinal cell apoptosis that normally occurs during the first 2 weeks after birth. Instead, overexpression of NT-3 promotes additional mitosis of DA cells at postnatal day 4, but does not affect cell mitosis before birth, the peak period of amacrine cell genesis in wild-type retinas. We next show that retinal explants cultured from birth to day 7 without extra NT-3 produced by lens exhibit similar number of DA cells as in wild type, further supporting the notion that postnatal overexpression of lens-derived NT-3 affects DA cell number. Moreover, the additional mitosis after birth in NT-3overexpressing mice does not occur in calretinin-positive amacrine cells or PKC-positive rod ON bipolar cells. Thus, the NT-3triggered wave of cell mitosis after birth is specific for the retinal DA cells.
\end{abstract}

\section{Introduction}

Dopamine modulates multiple functions in the retina, including neuronal differentiation and survival, eye growth, the relative gain of visual signaling, and circadian rhythm (Witkovsky, 2004). In adult retinas of several species, the total number and distribution of dopaminergic amacrine (DA) cells, identified by tyrosine hydroxylase (TH) immunoreactivity, are tightly regulated (Masland et al., 1993; Whitney et al., 2009; Keeley and Reese, 2010). DA cells constitute around one-hundredth of a percentage of total retinal neurons (Masland et al., 1993; Whitney et al., 2009), and they tile almost the whole retina (Raven et al., 2003; Whitney et al., 2009). During development, amacrine cell genesis peaks around embryonic day 14.5 (E14.5) in mice (Young, 1985; Cepko et al., 1996), with most DA cells born before birth (Evans and Battelle, 1987; Voinescu et al., 2009).

Received Feb. 25, 2011; revised June 10, 2011; accepted July 8, 2011.

Author contributions: M.Y., L.F., D.R.C., J.C., and X.L. designed research; M.Y., L.F., K.V.R., W.B., and X.L. performed research; D.R.C., J.C., and X.L. contributed unpublished reagents/analytic tools; M.Y., L.F., F.G., J.C., and X.L. analyzed data; M.Y., L.F., D.R.C., J.C., and X.L. wrote the paper.

This work was supported by a Midwest Eye-Banks research grant (X.L.), The Naito Foundation Subsidy for InterInstitute Researches (M.Y.), Research to Prevent Blindness (D.R.C.), and NIH-National Eye Institute Grants R01 EY001869 (D.R.C.), R01 EY018621 (J.C.), and R01 EY019034 (X.L.).

The authors declare no competing financial interests.

*M.Y. and L.F. contributed equally to this work.

Correspondence should be addressed to Xiaorong Liu, Department of Neurobiology and Physiology, Northwestern University, Evanston, IL 60208. E-mail: xiaorong-liu@northwestern.edu.

DOI:10.1523/JNEUROSCI.1100-11.2011

Copyright $\odot 2011$ the authors $\quad 0270-6474 / 11 / 3112663-11 \$ 15.00 / 0$
Many studies suggest that neurotrophins can regulate DA cell number and morphology (Cellerino et al., 1998; Calamusa et al., 2007; Liu et al., 2007; Grishanin et al., 2008; Landi et al., 2009). For example, the density of type II DA cells increases with injection of BDNF or neurotrophin-3 (NT-3) in the rat retina (Cellerino et al., 1998). In BDNF knock-out mice or mice with TrkB, the high-affinity receptor for BDNF, conditionally eliminated within the retina, the complexity of neuronal processes of DA cells is reduced (Cellerino et al., 1998; Grishanin et al., 2008). However, it is still unclear how neurotrophins regulate DA cell number. Some studies suggest that neurotrophins protect cells from apoptosis, which in turn increases the relative cell number in the retina (Frade et al., 1999; Cui and Harvey, 2000), but other studies show that neurotrophins do not affect the final number of retinal neurons remaining after the wave of programmed cell death (Pollock et al., 2003). Neurotrophin signaling could also influence neural differentiation by interacting with transcription factors in the retina (Liu et al., 2004; de Melo et al., 2008). Little is known about whether NT-3 specifically regulates DA cell number by preventing programmed cell death or stimulating genesis of new DA cells.

Given the expression of NT-3 in DA cells (Seki et al., 2004; Liu et al., 2009) and its action in regulating of DA cell number, we explored the underlying regulatory mechanisms using a transgenic mouse model in which NT-3 is continuously overexpressed in the eyes (Lavail et al., 2008; Liu et al., 2009). We determined how the density and morphology of DA cells were affected in the 
NT-3 overexpression (NT-3 OE) mice. After confirming a significant increase in DA cell number in NT-3 OE mice, we showed that this increase was not caused by a lower than normal rate of retinal apoptosis, but an increase of birth of new DA cells. Finding evidence for a promiscuous DA cell differentiation at P4, we further revealed that other classes of retinal neuron were not affected. Together, our results demonstrate that overexpression of NT-3 stimulates a new wave of DA cell genesis after birth.

\section{Materials and Methods}

Animals. Transgenic mice expressing NT-3 driven by an $\alpha$ A-crystallin promoter were generated, crossed to C57BL/6J background, and characterized (Robinson et al., 1995; Lavail et al., 2008; Liu et al., 2009). Mice were reared in $12 \mathrm{~h} \mathrm{light/darkness.} \mathrm{All} \mathrm{animal} \mathrm{procedures} \mathrm{conformed} \mathrm{to} \mathrm{the} \mathrm{guidelines} \mathrm{on}$ the Use of Animals in Neuroscience Research from the NIH and were in accordance with protocols approved by Northwestern University.

Immunohistochemistry in the mouse retina. Immunohistochemistry was performed following our published procedure (Liu et al., 2007). For embryonic retinas, heads were fixed in $4 \%$ paraformaldehyde (PFA) in $0.1 \mathrm{~m}$ PBS, $\mathrm{pH} 7.4$, for $1-2 \mathrm{~h}$, cryoprotected in $10 \%$ and then $20 \%$ sucrose in PBS overnight. Cryostat sections $(16 \mu \mathrm{m})$ or whole-mounted retinas were prepared for immunostaining (Feng et al., 2006; Liu et al., 2007). Two TH antibodies, rabbit anti-TH antibody (AB152; Millipore) and mouse anti-TH antibody (MAB318; Millipore), were tested and exhibited similar staining pattern (data not shown). Because rb-TH antibody stains processes better with lower background than the ms-TH antibody in the mouse retina (data not shown), we used the rb-TH antibody in this study. We also used rabbit anti-protein kinase $\mathrm{C} \alpha(\mathrm{PKC} \alpha)$ (Millipore Bioscience Research Reagents; 1:1000) for rod ON bipolar cells and rabbit anti-calretinin antibody (Millipore Bioscience Research Reagents; 1:500) for cholinergic amacrine cells. Sections or whole-mounted retinas were then incubated with secondary antibodies conjugated to Alexa Fluor 488, or Alexa Fluor 594 (diluted 1:500-1:1000; Invitrogen) and coverslipped (Liu et al., 2007). Images were taken with the Zeiss Discovery V8 dissecting microscope and Zeiss confocal microscope (Zeiss Pascal; Zeiss).

For cell densities, we counted 4-10 standardized areas per retina in whole-mounted retinas. Because TH immunostaining was weak at P3, we counted all cells containing TH signals in the projected images of the confocal $Z$-stacks. For bipolar cells, we counted three to six areas in retinal sections (see Fig. 9). Each experimental group included 4-10 retinal samples (see details in Results).

To quantify the density of TH-immunopositive processes, projections of the confocal $Z$-stacks were acquired using ImageJ. We chose areas devoid of DA cell bodies and thick primary processes. All images were first thresholded to the same level and then the density of $\mathrm{TH}$-immunoreactive processes was measured using the Integrated Density function in ImageJ (Grishanin et al., 2008).

Morphometric analysis. Several measures were used to quantify cell distribution, including the nearest neighbor $(\mathrm{NN})$, the Voronoi domain analysis, and the density recovery profile (DRP) of cell distribution. We used a custom-written semiautomatic algorithm in MATLAB to find cell centers in retinal images. For each retina, two to four images immunostained with anti-TH antibody were processed by LSM5 Image Browser and Adobe Photoshop to facilitate the following MATLAB morphometric analysis. For NN analysis, we rejected cells close to the border of the image (i.e., that they could have potential closer neighbors outside the image) (see examples in Fig. $2 \mathrm{~A}$ ). We then computed the distance between each selected cell and its nearest neighbor. For the Voronoi analysis, we computed the Voronoi diagram of the cell centers in each image, and measured the size of the Voronoi domain of each cell. Again, we rejected cells whose Voronoi domains were close to the border of the image (see examples in Fig. 2B).

For the DRP analysis, one cell was considered as the origin, and the distance of every other cell relative to the origin was computed. This was repeated for every cell in the image, resulting in an autocorrelogram of cell distribution, from which was derived a DRP curve. In other words, DRP describes the relative density of DA cells at increasing distances from each cell (Raven et al., 2003). DRP curves prepared from each animal were then averaged for each experimental group, and then nor- malized by their mean DA cell density. To simulate random distributions of DA cells, we generated 20 random samples with the same cell density as in each NT-3 OE image ( $n=5$ images). We computed a corresponding average random DRP of the 20 simulated samples, and then averaged these DRPs and computed the SEs to obtain the global DRP of the random simulations.

Apoptosis. Terminal deoxynucleotidyl transferase (TdT)-mediated dUTP nick end labeling (TUNEL) was performed at P4, P7, and P13 using the In Situ Cell Death Detection Kit, Fluorescein (Roche) (Sennlaub et al., 2002; Fuerst et al., 2008). In brief, following fixation with $4 \%$ PFA for $15 \mathrm{~min}$, samples were permeabilized on ice for $2 \mathrm{~min}$ using a solution of $0.1 \%$ sodium citrate and $0.1 \%$ Triton X-100 in PBS, then microwaved in $0.1 \mathrm{M}$ citrate buffer, $\mathrm{pH} 6.0$, for $1 \mathrm{~min}$ at $725 \mathrm{~W}$. Samples were then blocked for $30 \mathrm{~min}$ in a solution of $0.1 \mathrm{M}$ Tris- $\mathrm{HCl}, 3 \%$ of BSA, and $20 \%$ of normal bovine serum, and then incubated at $37^{\circ} \mathrm{C}$ for $1 \mathrm{~h}$ with the TdT enzyme and the fluorescein label solution. For positive controls, the sections were incubated for $10 \mathrm{~min}$ with DNase before permeablization. The negative controls lacked the TdT enzyme during the labeling process. Following TUNEL staining, the samples were immunostained with anti-TH antibodies. TUNEL-positive cells were counted in the neuroblastic layer (NBL) or the inner nuclear layer (INL) next to the optic nerve on the retinal sections.

Cell mitosis. To identify mitotic cells, $10 \mathrm{~mm}$ 5-bromo-2'-deoxyuridine (BrdU) (Sigma-Aldrich) with 15\% DMSO in PBS was injected into pregnant mice $(20 \mu \mathrm{l} / \mathrm{g}$ of body weight $)$ or into pups $(30 \mu \mathrm{l} / \mathrm{g})$ intraperitoneally and/or subcutaneously. It was estimated that $\mathrm{BrdU}$ was available for mitotic cells undergoing their last S-phase for $\sim 1-2 \mathrm{~h}$ following injection (Voinescu et al., 2009). Therefore, heads of embryonic mice or eyes of pups were dissected $1 \mathrm{~h}$ after injection at E13.5 and E15.5, and $2 \mathrm{~h}$ after injection at P2 and P4, respectively. BrdU incorporated into mitotic cells was stained with antiBrdU antibody (Developmental Studies Hybridoma Bank). To double label mitotic cells with other retinal markers, we injected BrdU at P3 and P4 (100 $\mu \mathrm{g} \mathrm{BrdU} / \mathrm{g})$. Two weeks after injection of BrdU, retinas were dissected and immunostained with different cell-specific markers.

Two antibodies were used to detect M-phase of mitotic cells: Antiphosphohistone H3 (Ser10), clone 3H10, FITC conjugate (Millipore; labeled as 3H10) and phosphohistone H3-Ser 10 (Santa Cruz Biotechnology; labeled as PhH3) (Pan et al., 2005; Chen et al., 2009). These two antibodies gave similar staining patterns in the mouse retinas (data not shown). In this study, we mainly used $\mathrm{PhH} 3$ antibody because it gave stronger signal than $3 \mathrm{H} 10$ (data not shown).

BrdU or PhH3-positive cells were counted in two areas separately: central is the area next to the optic nerve and peripheral is the edge area in retinal sections (see Figs. 5A, 6A). We analyzed three to five sections per retina and each experimental group included three to six retinas.

Retinal explant culture. Pups were killed at P0. Retinas and pigmented epitheliums without lens were dissected and placed on Millicell inserts (Millipore) and then transferred to six-well culture plates containing 1 $\mathrm{ml}$ of culture medium (50\% MEM with HEPES, 25\% Hanks solution, $25 \%$ heat-inactivated fetal calf serum, $25 \mathrm{U} / \mathrm{ml}$ penicillin, $25 \mu \mathrm{g} / \mathrm{ml}$ streptomycin, $200 \mu \mathrm{M}$ L-glutamine, and $5.75 \mathrm{mg} / \mathrm{ml}$ glucose) in each well. Retinal explant samples were cultured at $37^{\circ} \mathrm{C}$ in $5 \% \mathrm{CO}_{2}$ for $7 \mathrm{~d}$, and the medium was changed every other day (Hatakeyama and Kageyama, 2002). Whole-mounted retinas were prepared for immunostaining and TH-positive cells were counted as described above.

\section{Results}

\section{Overexpression of NT-3 increases DA cell density}

To study whether and how NT-3 modulates DA cell development, we used transgenic mice that continuously overexpress NT-3 from lens fibers under the control of the $\alpha$ A-crystallin promoter (Lavail et al., 2008; Liu et al., 2009). In the adult (P30-P40) WT retina, the average density of DA cells, as identified by TH immunostaining, was $29 \pm 2$ cells $/ \mathrm{mm}^{2}$ ( $n=9$ retinas; Fig. $1 A-$ $C$ ), consistent with the previous findings that DA cells are one of the most sparsely distributed amacrine cells in the mouse retina (Raven et al., 2003). In the NT-3 OE retinas, the DA cell density was more than three times higher $\left(100 \pm 7\right.$ cells $/ \mathrm{mm}^{2} ; n=5$ 

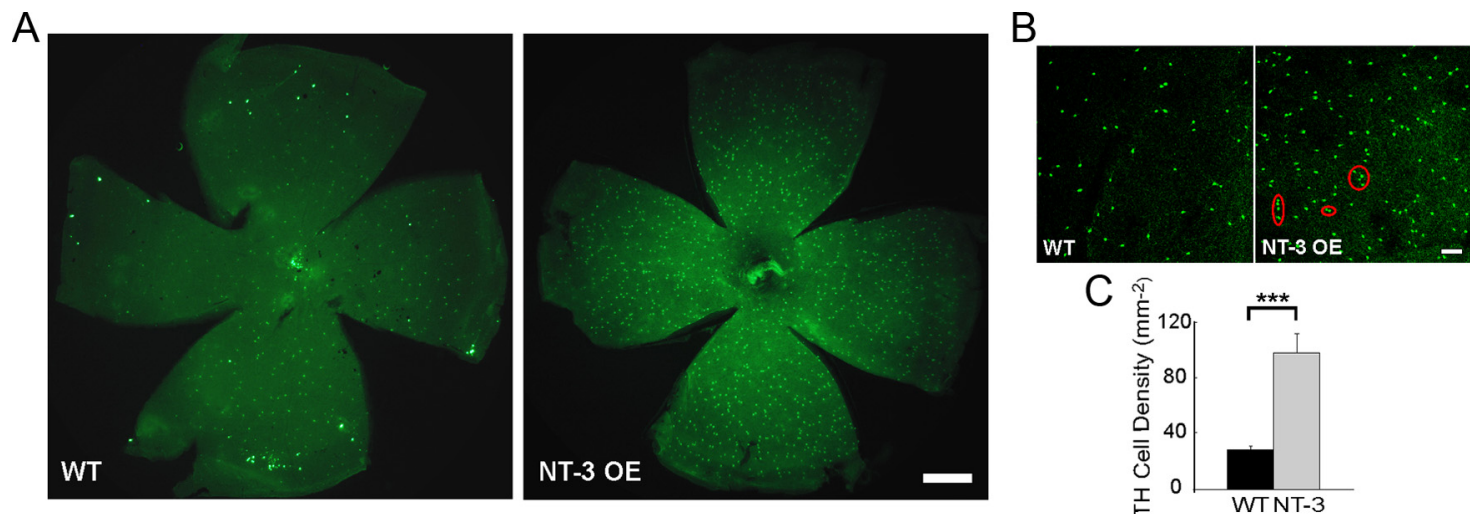

Figure 1. NT-3 OE upregulates the number of TH-positive DA cells. $A, B$, Images of flat-mounted mouse retinas immunostained with TH antibody show that more TH-positive cells were present in NT-3 OE mice. Scale bars: $\boldsymbol{A}, 500 \mu \mathrm{m} ; \boldsymbol{B}, 100 \mu \mathrm{m}$. The red circles show that DA cells clustered in the NT-3 OE retina. $\boldsymbol{C}$, The number of TH-positive cells in NT-3 OE mice was significantly increased compared with WT controls. ${ }^{* * *} p<0.001$ in Student's $t$ test. Error bar represents SE.

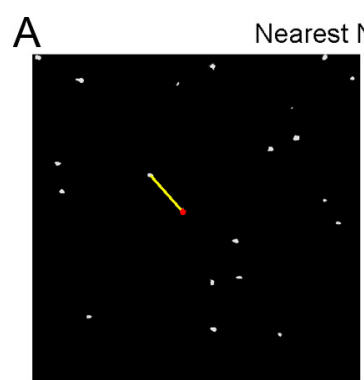

WT

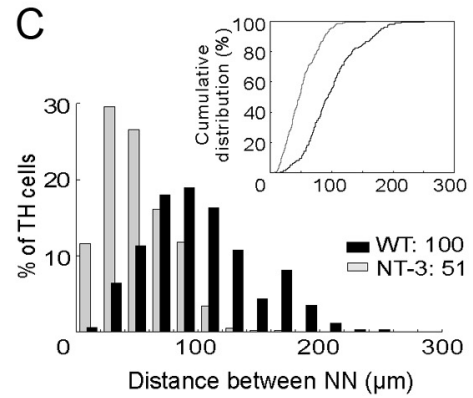

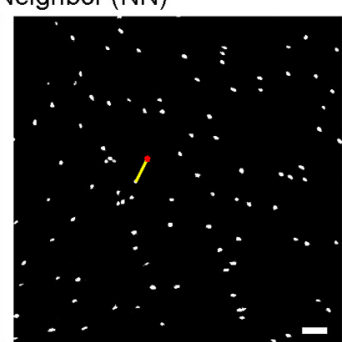

NT-3 OE
B

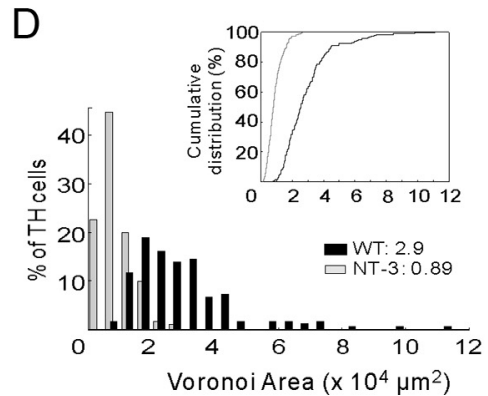

Voronoi

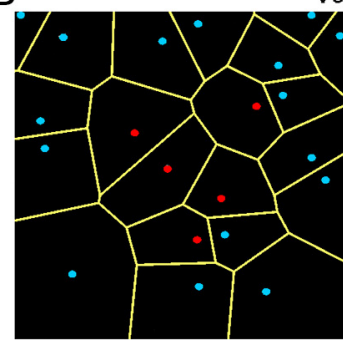

WT

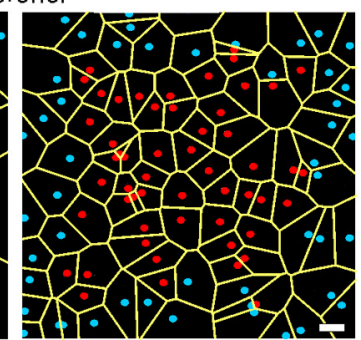

NT-3 OE

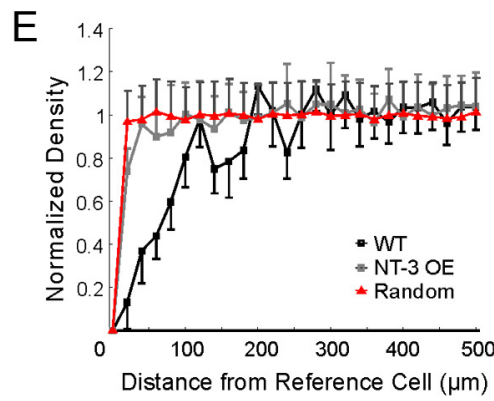

Figure 2. DA cells in NT-3 OE mice become randomly distributed over the retina. $\boldsymbol{A}$, Examples for the NN analysis in processed image of WT and NT-3 0 E retinas. $\boldsymbol{B}$, Processed Voronoi images for analyzing spacing properties of WT and NT-3 OE retinas. Selected cells appear in red and rejected cells in blue. Light yellow partitions show the area occupied by each cell. Scale bar, $100 \mu \mathrm{m}$. $C$, Histogram and the cumulative distribution (inset) of the NN show that the distance between the nearest TH-positive cells in NT-30E mice was significantly shorter than that in WT mice. $\boldsymbol{D}$, Histogram and the cumulative distribution (inset) of Voronoi areas show that TH-positive cells in NT-3 OE mice occupied smaller area than in WT mice. Bin width: C, $20 \mu \mathrm{m} ; \boldsymbol{D}, 5000 \mu \mathrm{m}^{2} . p<0.001$ in K-S test. $\boldsymbol{E}$, Normalized DRPs show that the DRP generated from average of 100 random simulations (labeled as "random") was very similar to the DRP of NT-3 OE mice.

retinas; $p<0.001$ in Student's $t$ test) than that in the WT retinas (Fig. $1 A-C$ ). We then examined how the distribution pattern of DA cells might have been changed in the NT-3 OE retinas.

We analyzed how overexpression of NT-3 changed the spacing properties of TH-positive cells using two methods: the distance between nearest-neighbor cells (NN analysis) (Fig. 2A,C) and the area "occupied" by each DA cell (the Voronoi domain analysis) (Fig. $2 B, D)$. The mean distance to the nearest neighbor in adult NT-3 OE retina was $51 \pm 1 \mu \mathrm{m}(n=5$ retinas $)$, significantly shorter than that in WT $[100 \pm 4 \mu \mathrm{m} ; n=9$ retinas; $p<0.001$ in KolmogorovSmirnov (K-S test); Fig. 2C]. In fact, many more DA somata clustered in NT-3 OE retinas: $11.6 \%$ of DA cells had at least one neighbor within $20 \mu \mathrm{m}$ distance, while in WT retinas, only $0.58 \%$ of DA cells had a neighbor within $20 \mu \mathrm{m}$ from its center (Fig. 2C).

The Voronoi domain analysis computes a set of territories occupied by individual cells. In other words, any position within a
Voronoi domain is closer to the given cell than to any other cells. It thus reflects the distance between a DA cell to its multiple neighbors and gives an estimate of local density of DA cells (Fig. 2B). Consistent with the $\mathrm{NN}$ analysis, we found that the Voronoi domain was much smaller in NT-3 OE mice than that in WT (NT-3 OE, $0.89 \pm$ $0.03 \times 10^{4} \mu \mathrm{m}^{2}$; WT, $2.9 \pm 0.2 \times 10^{4} \mu \mathrm{m}^{2} ; p<0.001$ in K-S test; Fig. $2 D$ ). In WT retinas, almost no DA cells were found to occupy areas smaller than $5000 \mu \mathrm{m}^{2}$ (Fig. 2D), which was known as the "exclusion zones" for individual DA cells (Raven et al., 2003). By contrast, $22.6 \%$ of DA cells in NT-3 OE retinas occupied such small areas (Fig. 2D). Together, our data demonstrate that NT-3 overexpression results in more densely packed DA cells. Moreover, some DA cells are clustered together much more than in WT retinas.

We further plotted the DRP, which describes the mean density of DA cells relative to a center cell at increasing distance (Raven et al., 2003). DRPs were calculated and averaged for WT ( $n=9$ retinas) 
A

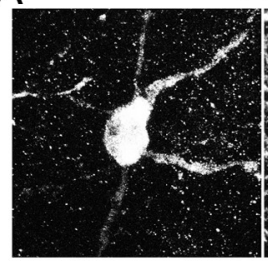

WT

$\mathrm{D}$

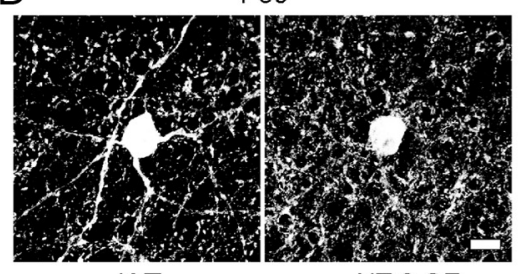

WT
P10

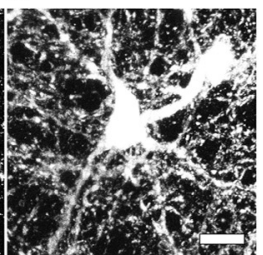

NT-3 OE

NT-3 OE
B

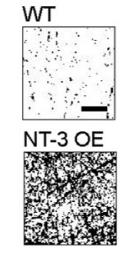

$E$
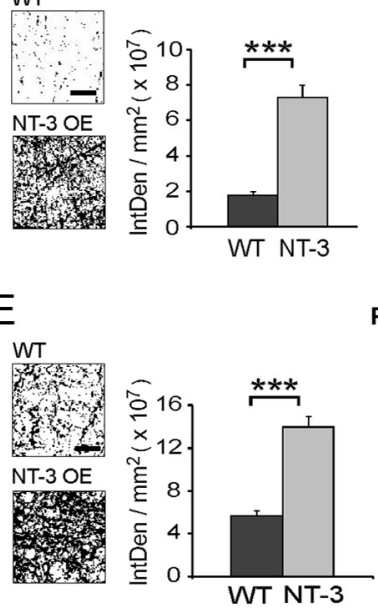

P10

P30
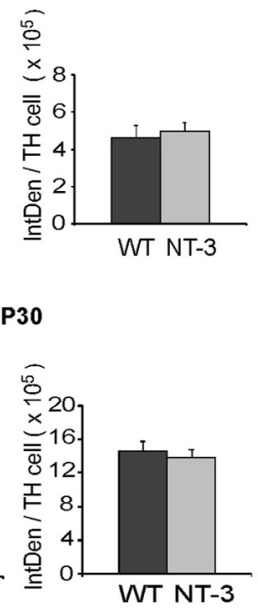

C

$\mathrm{F}$
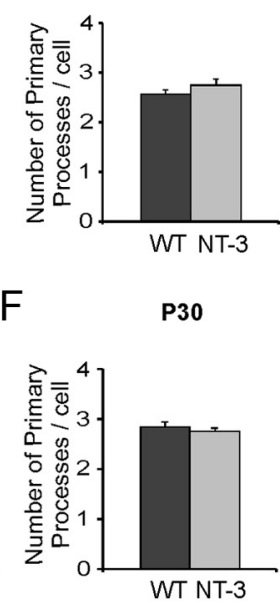

Figure 3. DA cells exhibit a largely normal dendritic density in NT-3 OE mice. $\boldsymbol{A}, \boldsymbol{D}$, Immunostaining of TH-immunoreactive processes at P10 (A) and P30 (D). Scale bar, $10 \mu \mathrm{m}$. $\boldsymbol{B}, \boldsymbol{E}$, TH-immunoreactive processes of DA cells were threefold to fourfold stronger in NT-3 OE mice than WT controls at P10 $(\boldsymbol{B})$ and P30 $(\boldsymbol{E})$. After normalized by the DA cell density at P10 $(\boldsymbol{B})$ and P30 $(\boldsymbol{E})$, the difference in the integrated density of DA cell processes disappeared. Inset images: WT and NT-3 OE retinas immunostained with anti-TH antibody processed in Image J for integrated density analysis. Scale bar, $20 \mu \mathrm{m}$. $\boldsymbol{C}, \boldsymbol{F}$, No difference in the number of primary processes of TH-positive cells at P10 ( $(\boldsymbol{C})$ and P30 $(\boldsymbol{F})$ was found between WT and NT-3 OE retinas. ${ }^{* *} p<0.001$ in Student's $t$ test. Error bar represents standard error of the mean.

and NT-3 OE $(n=5)$, and then normalized by their own mean DA cell density (Fig. 2E). Our data confirmed that the probability of finding another DA cell within $50 \mu \mathrm{m}$ from any cell was much lower in WT than in NT-3 OE retinas. This is in agreement with the idea that DA cells tend to keep a larger distance between each other to form the mosaic regularity (Raven et al., 2003). By contrast, in NT-3 OE retina, the relative density of DA cells already reached the mean density within this $50 \mu \mathrm{m}$ range (Fig. $2 E$ ), consistent with our above data that the minimal spacing constraints were abolished in NT-3 OE retinas.

To get an idea of the randomness of DA distribution in NT-3 OE retinas, we generated and averaged 100 random samples (20 per image $\times 5$ images) with the same cell density (labeled as random; Fig. 2E). We found that the DRP distribution of WT retinas was significantly different from the distribution created by random simulated distributions $(p<0.001$, K-S test with DRPs estimated on 100 bins). At the same time, the DRP of NT-3 OE retina was very similar to the DRP of the random distribution (Fig. $2 E)$. Our data suggest that overexpression of NT-3 results in an increase of DA cell density and their distribution is shifted from a tile-like to a random-like pattern.

The mean density of DA cell plexus in NT-3 OE mice is comparable with those in WT mice

With the threefold increase in DA cell density in NT-3 OE retinas, we noticed that the packing of these DA cell processes was denser than that in WT mice (Fig. 3A). To examine whether the processes of individual DA cells were altered

A
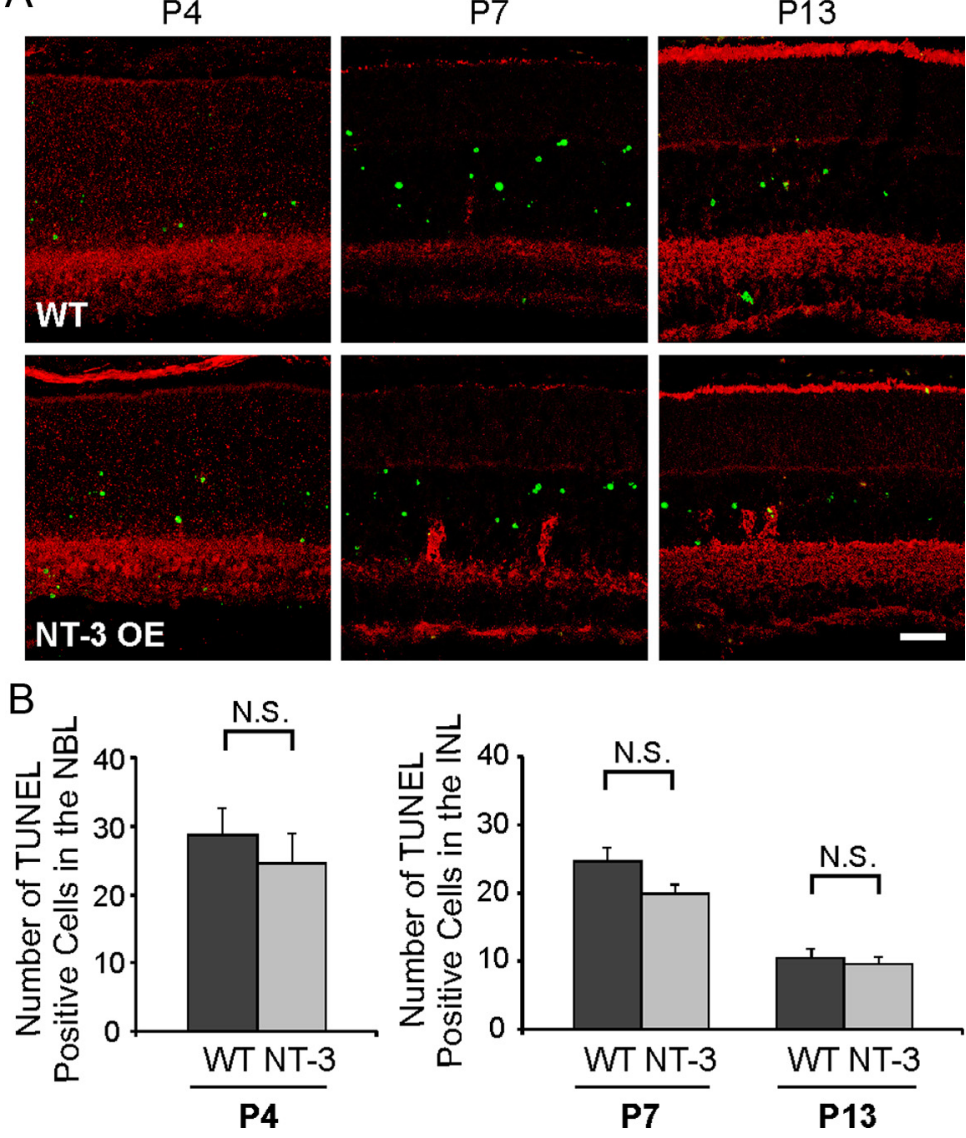

Figure 4. Overexpression of NT-3 does not affect overall cell apoptosis during postnatal development. $A$, Double labeling with TH (red) and TUNEL (green) of retinal sections from WT (top) and NT-3 OE mice (bottom) at P4, P7, and P13. Scale bar, $50 \mu \mathrm{m}$. B, No difference was found in the number of TUNEL-labeled apoptotic cells in the NBL at P4 and in the INL at P7 and P13 between WT and NT-3 OE mice. N.S., Not significant $(p>0.05)$ in Student's $t$ test. Error bar represents standard error of the mean.

in NT-3 OE mice, we analyzed the dendritic density of THpositive cells at $\mathrm{P} 10$ when $\mathrm{TH}$ signals in processes first became discernible. Because the TH-positive dendrites from neighboring cells heavily overlapped, we found it hard to trace the dendritic 
A

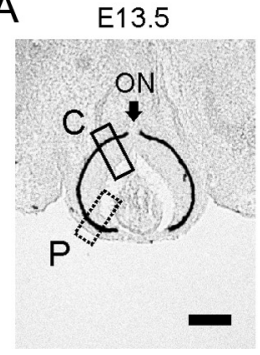

P2

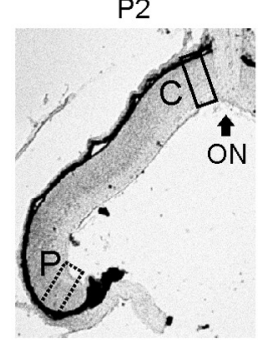

E13.5
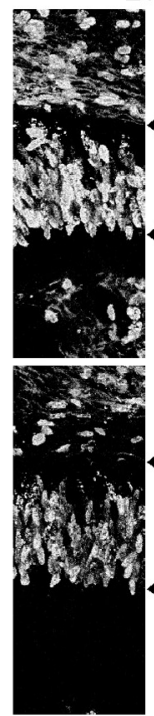

C
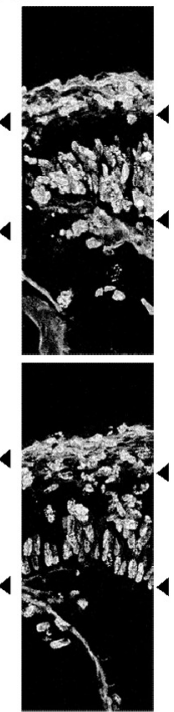

P
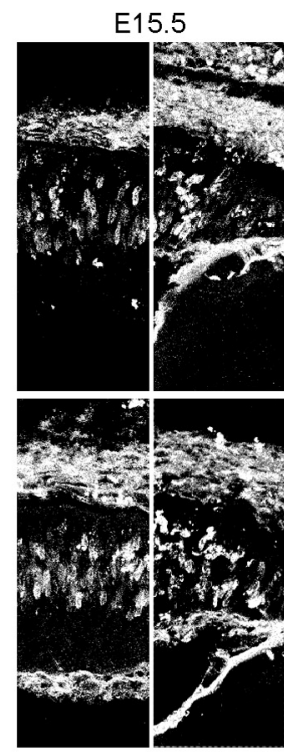

C
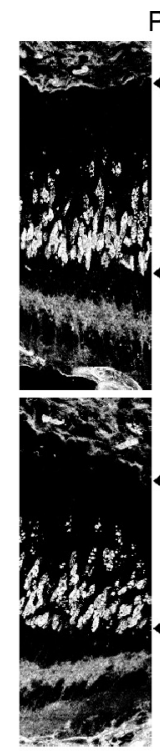

C
$P 2$
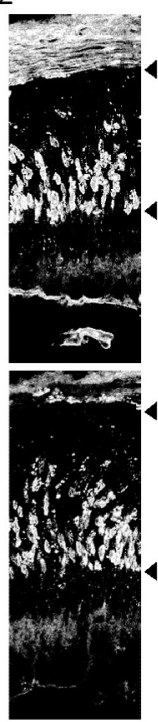

$P$
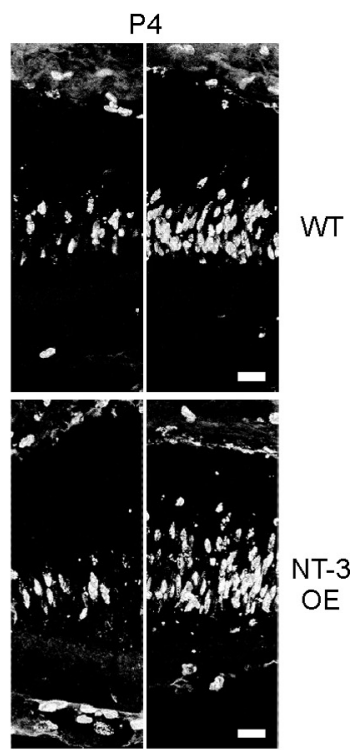

C
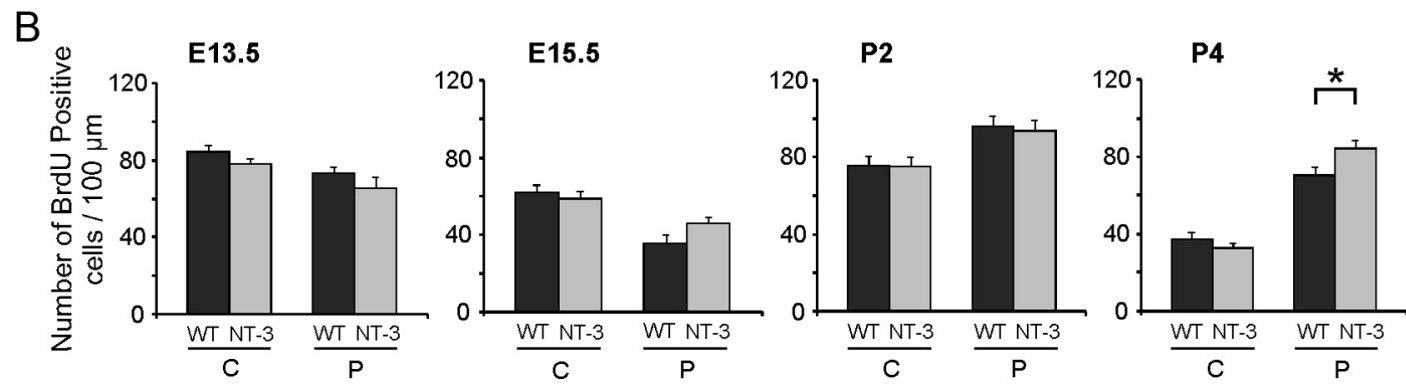

Figure 5. Overexpression of NT-3 increases S-phase mitotic cells in the peripheral retina at P4. A, Low-magnification images of retinal sections of WT mice at E13.5 and P2. BrdU-positive cells in the central and the peripheral retinas of WT (top panel) and NT-3 OE (bottom panel) at E13.5, E15.5, P2, and P4. The arrow indicates the optic nerve (ON). Central (C) and peripheral (P) areas were marked with solid and dashed squares, respectively (same in Fig. 6 A). The arrowheads indicate the NBL. Scale bars: $200 \mu \mathrm{m}$ (in the bright-field images); $20 \mu \mathrm{m}$ (in images with BrdU staining). $\boldsymbol{B}$, Quantification of the number of BrdU-positive cells in the NBL at four different ages shows an increase of BrdU-positive cells in the peripheral retina at P4 in NT-3 0 E mice. ${ }^{*} p<0.05$; ${ }^{* * *} p<0.001$ in Student's $t$ test (same in Figs. 6-9). Error bar represents standard error of the mean.

trees of individual DA cells. Therefore, we quantified the THimmunopositive processes in WT and NT-3 OE retinas using the Integrated Density function in NIH ImageJ (Fig. 3B) (Grishanin et al., 2008). The mean value was approximately fourfold higher in NT-3 OE mice than that in WT mice (NT-3 OE, $7.3 \pm 0.7 \times$ $10^{7}$; WT, $1.8 \pm 0.3 \times 10^{7} ; p<0.001$, Student's $t$ test; Fig. $3 B$, left). After normalizing by DA cell density, we found no significant difference in the mean density of TH-positive processes between WT and NT-3 OE mice (NT-3 OE, $5.0 \pm 0.5 \times 10^{5}$; WT, $4.6 \pm$ $0.7 \times 10^{5} ; p=0.70$; Fig. $3 B$, right). Additionally, we compared the number of primary dendrites emerging from the DA cell somata (Fig. 3C). The number of primary processes was not different between NT-3 OE and WT retinas (NT-3 OE, $2.8 \pm 0.1$; WT, $2.6 \pm 0.1 ; p=0.26$; Fig. $3 C$ ). These results suggest that the dendritic network of DA cells became denser as a result of more DA cells in NT-3 OE retinas, but the mean density of DA cell plexus was not altered in neonatal mice.

In WT retina, the TH-immunoreactive processes that form the complex network at the border of the INL and the inner plexiform layer continue to develop after eye opening $(\sim \mathrm{P} 13)$ (Nguyen-Legros et al., 1983; Sharma, 2001). We thus further examined whether overexpression of NT-3 affected the DA cell dendritic network in older animals (Fig. 3D,E). At P30, the processes were denser than at $\mathrm{P} 10$ in WT $\left(5.6 \pm 0.5 \times 10^{7}\right.$ at $\mathrm{P} 30$ vs $1.8 \pm 0.3 \times 10^{7}$ at $\mathrm{P} 10 ; p<0.001$, Student's $t$ test). The overall dendritic network of DA cells at $\mathrm{P} 30$ was still significantly denser in NT-3 OE mice than that in WT mice (NT-3 OE, $13.9 \pm 1.1 \times 10^{7}$; WT, $5.6 \pm 0.5 \times 10^{7} ; p<0.001$; Fig. 3E, left). After normalized by DA cell density, no difference in the complexity of DA cell processes between WT and NT-3 OE mice was found at P30 (NT-3 OE, $13.8 \pm$ $1.0 \times 10^{5} ; \mathrm{WT}, 14.5 \pm 1.3 \times 10^{5} ; p=0.68 ; \mathrm{Fig} .3 E$, right graph). Wealso compared the number of primary dendrites emerging from the DA cell somata at P30 and found no difference between NT-3 OE and WT retinas (NT-3 OE, $2.7 \pm 0.1 ; \mathrm{WT}, 2.8 \pm 0.1 ; p=0.49$; Fig. $3 F$ ).

Together, our data showed that overexpression of NT-3 led to an increase of DA cell density and their somata became more randomly distributed over the retina. Consequently, the dendritic network of DA cells became denser. We interpreted these findings as evidence that the increased dendritic density resulted simply from the presence of more DA cells. Next, we investigated the developmental mechanisms by which NT-3 overexpression led to an increase of DA cell density. Because neurotrophins were known to promote both neuronal survival and differentiation in the CNS (Huang and Reichardt, 2001), we examined whether the increased number of DA cells in NT-3 OE retinas was due to a decrease of cell apoptosis or an increase in cell mitosis.

\section{Overexpression of NT-3 does not affect cell apoptosis}

A wave of programmed cell death occurs in mouse retina during the first two postnatal weeks (Young, 1984; Linden and Pinto, 
1985). To quantify and compare the rate of cell death in WT and NT-3 OE retinas, we examined the number of TUNELlabeled apoptotic cells at P4, P7, and P13 (Fig. 4). Overall, we found no difference between WT and age-matched NT-3 OE retinas in the mean number of TUNELlabeled cells (Fig. 4). In WT retinas, consistent with apoptosis peaking during the first postnatal week, we found more apoptotic cells at P4 (29 \pm 4 cells; $n=3$ retinas) and at P7 ( $25 \pm 2$ cells; $n=5$ retinas $)$ than that at $\mathrm{P} 13$ ( $11 \pm 1$ cells; $n=3$ retinas; Fig. $4 B$ ). We observed similar number of cells undergoing apoptosis in NT-3 OE retinas at these three ages (P4: $25 \pm 4$ cells, $n=3$ retinas, $p=0.49$; P7: $20 \pm 1$ cells, $n=6$ retinas, $p=0.08$; P13: $9 \pm$ 1 cells, $n=4$ retinas, $p=0.57$, Student's $t$ test; Fig. $4 B$ ). Our data therefore show that the increase of DA cell number is unlikely due to a decrease of cell apoptosis in NT-3 OE mice.

\section{Overexpression of NT-3 does not affect} cell mitosis before birth

We next examined whether overexpression of NT-3 upregulated cell mitosis, which could lead to more cells differentiating into DA cells. Because most amacrine cells are born around E14.5 (Cepko et al., 1996; Voinescu et al., 2009), we pulse-labeled mitotic cells by injecting BrdU into pregnant mice at E13.5 and E15.5 (Fig. 5). We counted BrdU-positive cells in the central and peripheral areas separately because the two areas exhibited different patterns of mitotic activity (Young, 1985). No significant difference was found between WT and NT-3 OE mice at the two embryonic ages (at E13.5, central, $p=0.17$; peripheral, $p=0.27$; at E15.5, central, $p=0.60$; peripheral, $p=0.11$, Student's $t$ test; same below; Fig. $5 B)$. At E13.5, we found $84.6 \pm 3 \mathrm{BrdU}$-positive cells $/ 100 \mu \mathrm{m}$ at the central and $73.4 \pm 4$ cells $/ 100 \mu \mathrm{m}$ at the peripheral retinas in WT mice, not significantly different from those in NT-3 OE retinas (central, $78.1 \pm 3$ cells/100 $\mu \mathrm{m}$; peripheral, $65.3 \pm 6$ cells/ $100 \mu \mathrm{m}$ ). At E15.5, similar results were obtained (central, $61.8 \pm$ 4 cells $/ 100 \mu \mathrm{m}$ in WT and $58.6 \pm 4$ cell/100 $\mu \mathrm{m}$ in NT-3 OE; peripheral, $35.8 \pm 4$ cells $/ 100 \mu \mathrm{m}$ in WT and $45.6 \pm 4$ cells $/ 100$ $\mu \mathrm{m}$ in NT-3 OE). Our data therefore indicate that overexpression does not affect overall cell mitosis before birth.

\section{Overexpression of NT-3 promotes cell mitosis after birth}

Even though most amacrine cells were born before birth, we further examined cell mitosis during early postnatal development. At P2, no difference was detected between WT and NT-3 OE retinas (central, $p=0.96$; peripheral, $p=0.75$; Fig. $5 B$ ). However, at $\mathrm{P} 4$, more BrdU-positive cells were found in the peripheral retina of NT-3 OE mice than that of WT mice (NT-3 OE, $84 \pm 4$ cells $/ 100 \mu \mathrm{m}$; WT, $70 \pm 4$ cells $/ 100 \mu \mathrm{m} ; p<0.05$; Fig. $5 B)$, suggesting more cells were still differentiating at $\mathrm{P} 4$ in NT-3 OE retinas.

We confirmed that NT-3 overexpression promoted cell mitosis at P4 using another antibody against phosphohistone $\mathrm{H} 3$ (PhH3), a marker for M-phase mitotic cells (Fig. 6). In general,
PhH3 stains fewer cells than BrdU-pulse labeling and they were mainly found in the outer surface of the retina (OSR), which is apposed to the retinal pigment epithelium, at P2 and P4 (Fig. $6 A, B)$. Similar to the BrdU-labeling results, we found more mitotic cells at $\mathrm{P} 4$ in NT-3 OE retinas (Fig. 6C). In WT retina, $\mathrm{PhH} 3$-positive cells in central and peripheral retinas were quite low at P2 $(5.1 \pm 0.6$ and $5.0 \pm 0.7$ cells $/ 100 \mu \mathrm{m}$, respectively). No difference was detected in NT-3 OE retinas at this age (central: $4.2 \pm 0.6$ cells $/ 100 \mu \mathrm{m}, p=0.27$; peripheral: $5.2 \pm$ 0.8 cells $/ 100 \mu \mathrm{m}, p=0.88$; Fig. $6 C$ ). At $\mathrm{P} 4$, only a few positive cells were found in the peripheral area $(4.1 \pm 0.4$ cells $/ 100$ $\mu \mathrm{m})$, and almost no cells were labeled in the central area $(0.2 \pm 0.1$ cells $/ 100 \mu \mathrm{m})$ in the WT retinas (Fig. $6 C)$. By contrast, the number of PhH3-positive cells in NT-3 OE mice at P4 was significantly larger compared with WT in the central $(0.9 \pm 0.3$ cells $/ 100 \mu \mathrm{m} ; p<0.05)$ and the peripheral areas (6.6 \pm 0.5 cells $/ 100 \mu \mathrm{m} ; p<0.001$; Fig. $6 C$ ).

Because overexpression of NT-3 increased cell mitosis only at P4 and no difference in apoptosis was found after P4, we surmised that (1) there should be an increase after P4, and (2) there should be no difference before P4 in DA cell number. We counted directly the DA cell numbers on whole-mounted retinas and retinal sections at P2-P3 and P4-P6 (Fig. 7A-C). We found that, in the $\mathrm{P} 4-\mathrm{P} 6$ group, the number of TH-positive cells in NT-3 OE mice was $265 \pm 13$ cells $/ \mathrm{mm}^{2}$, significantly higher than that in WT mice $\left(143 \pm 12\right.$ cells $/ \mathrm{mm}^{2} ; p<0.001$; Fig. $\left.7 D\right)$. By contrast, at P3, there was no significant difference between WT and NT-3 OE retinas (WT, $393 \pm 61$ cells $/ \mathrm{mm}^{2}$; NT-3 OE, $443 \pm 58$ cells/ $\mathrm{mm}^{2} ; p=0.56$; Fig. $7 D$ ). A higher density of DA cells was found at $\mathrm{P} 3$ than $\mathrm{P} 4-\mathrm{P} 6$, presumably due to retinal growth and/or on- 
A

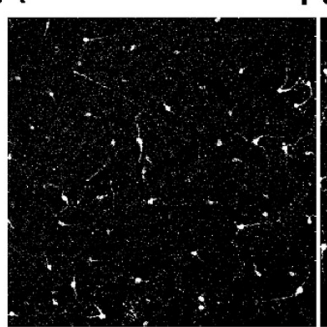

WT

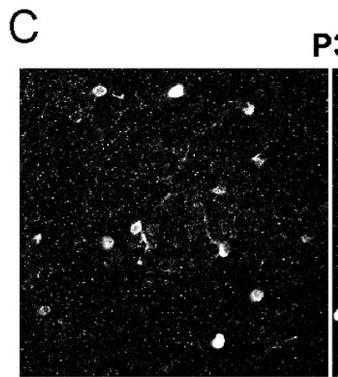

WT
P5

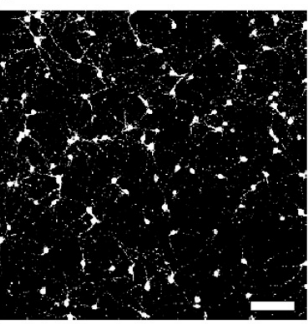

NT-3 OE

P3

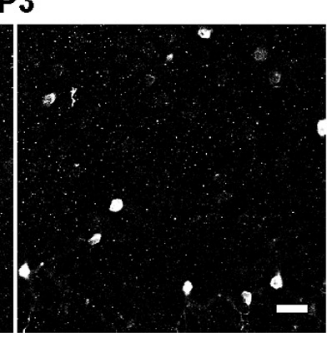

NT-3 OE
B

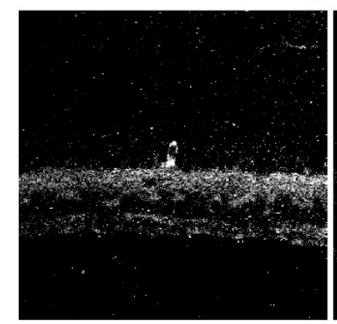

WT

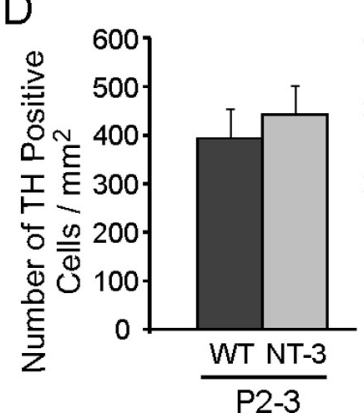

P4

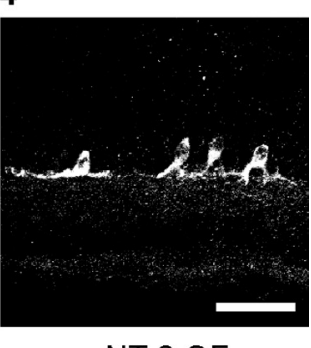

NT-3 OE

Figure 7. The number of TH-positive cells in NT-3 OE mice is significantly increased at P4 -P6 but not at P2-P3. $\boldsymbol{A}, \boldsymbol{C}$, TH-positive cells in whole-mount retinas from WT and NT-3 0 E mice at P5 $(\boldsymbol{A})$ and P3 (C). $\boldsymbol{B}$, TH-positive cells in retinal section of WT and NT-3 OE mice at P4. Scale bars: $\boldsymbol{A}, 100 \mu \mathrm{m} ; \boldsymbol{B}, 50 \mu \mathrm{m} ; \boldsymbol{C}, 20 \mu \mathrm{m}$. $\boldsymbol{D}$, More TH-positive cells were found at P4 -P6 but not at P2-P3 in NT-3 $\mathrm{OE}$ retinas. Error bar represents standard error of the mean.
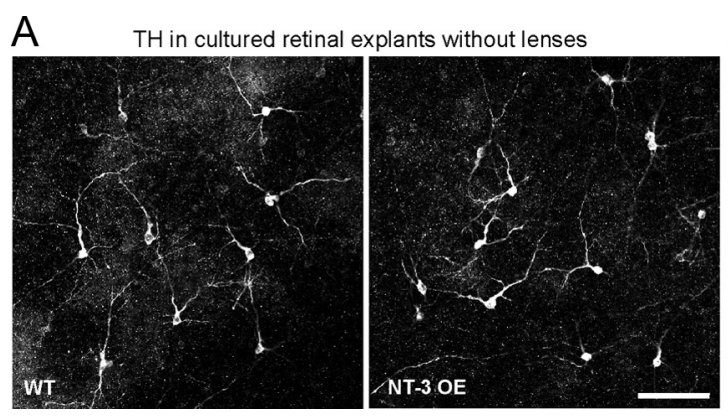

B

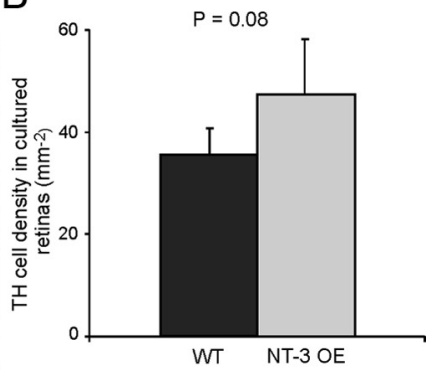

Figure 8. Retinas from NT-3 OE pups cultured in vitro without lenses show similar number of DA cells as in the cultured WT retinas. $\boldsymbol{A}$, Images of TH immunostaining in the WT and NT-3 OE retinal explants after $7 \mathrm{~d}$ in culture. Scale bar, $100 \mu \mathrm{m}$. $\boldsymbol{B}$, The TH cell density in cultured NT-3 OE retinas $(n=5)$ was not significantly different from that of cultured WT retinas $(n=6 ; p=0.08$ in Student's $t$ test). Error bar represents standard error of the mean.

going apoptosis. Given the decrease in DA cell density from $\mathrm{P} 2-\mathrm{P} 3$ to $\mathrm{P} 4-\mathrm{P} 6$, it is impossible to rule out a selective decreased apoptosis of DA cells in NT-3 OE mice. However, given the absence of NT-3 action on apoptosis (Fig. 4) and the increased number of DA-positive mitotic cells in the NT-3 OE mice, we consider that a major part of the increase of DA cell number can be attributed to the increase of mitosis.

To further support the model that lens-derived overexpression of NT-3 affects DA cell development after birth, retinas were dissected and cultured without lenses from birth for $7 \mathrm{~d}$ (see Materials and Methods). Without extra NT-3 produced by lens, the number of DA cells was similar to the WT number (WT: $36 \pm 5$ cells $/ \mathrm{mm}^{2}, n=6$ retinas; NT-3: $47 \pm 11$ cells/ $\mathrm{mm}^{2}, n=5$ retinas; $p=0.08$ in Student's $t$ test; Fig. 8 ), in contrast to the twofold increase seen in NT-3 OE mice in vivo at P4-P6 (Fig. 7D). Together, our data show that overexpression of NT-3 after birth, but not before birth, regulates DA cell number.
The increase of mitotic cells at P4 in NT-3 OE retinas leads to more DA cells but not cholinergic amacrine and rod ON bipolar cells

Normally, most postnatal mitotic cells are born into bipolar cells and rods, and only $\sim 1 \%$ differentiate into amacrine and ganglion cells (Young, 1985). Here, we found more mitotic cells at P4 in the NT-3 OE retinas, which led us to investigate further whether these additional mitotic cells in NT-3 OE retinas had indeed differentiated into DA cells (Fig. 9). We pulselabeled mitotic cells at P3 and P4 with BrdU. At P16, the retinas were doubleimmunolabeled with antibodies against $\mathrm{TH}$ and BrdU (Fig. 9A). The number of BrdU-positive cells in the inner INL where $\mathrm{TH}$ cell bodies was found slightly increased (WT, $6.5 \pm$ $0.6 \times 10^{3}$ cells $/ \mathrm{mm}^{2}$; NT-3 OE, $7.9 \pm 0.4 \times 10^{3}$ cells $\left./ \mathrm{mm}^{2}\right)$, but it did not reach significant level $(p=0.06$; Fig. $9 B)$. Importantly, almost no TH cells were colabeled with BrdU at P16 in WT retinas $(1.0 \pm 1.7 ; n=3$ retinas; Fig. $9 A, C)$. By contrast, in NT-3 OE retinas, a lot more cells were colabeled with BrdU and $\mathrm{TH}$ antibodies $(18.3 \pm 6.8 ; n=3$ retinas; $p<0.05$ in Student's $t$ test; Fig. $9 A, C)$. This indicates that the dividing cells at $\mathrm{P} 4$ indeed differentiate into DA cells. In other words, the differentiation of precursor neurons into DA cells after birth is increased in NT-3 OE mice.

This spurt of differentiation around $\mathrm{P} 4$ was not generalized across all classes of retinal neuron. We immunolabeled calretinin cholinergic amacrine cells in the INL and displaced amacrine cells and RGCs in the GCL (Fig. 10). We found comparable numbers of BrdU cells in the INL in WT and NT-3 OE retinas (WT, $128.7 \pm 4$ cells $/ 100 \mu \mathrm{m}$; NT-3 OE, $122.5 \pm 4$ cells $/ 100 \mu \mathrm{m} ; p=$ 
A
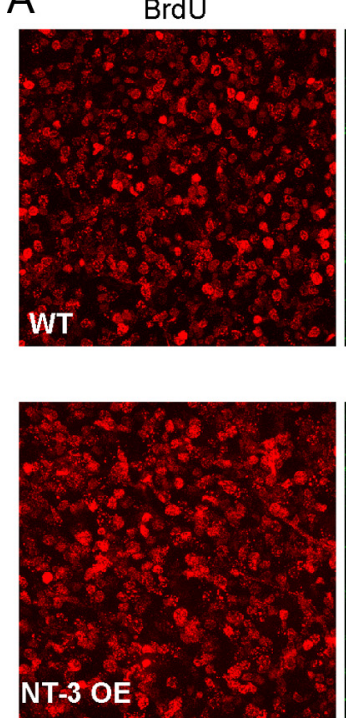

$\mathrm{TH}$
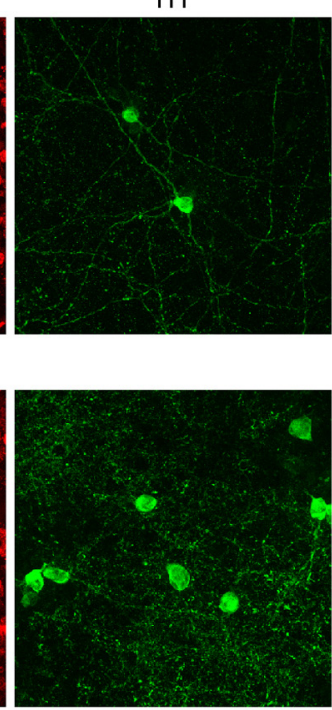

Merged
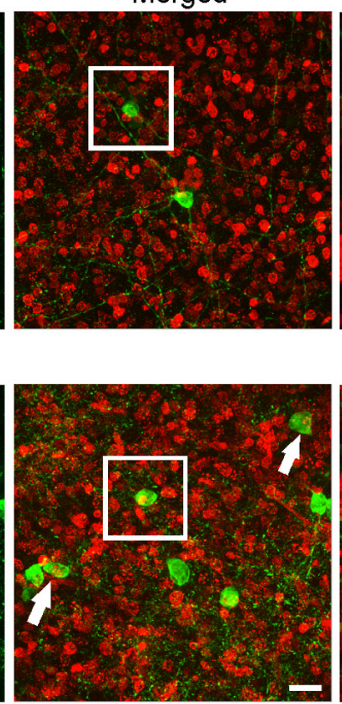

B
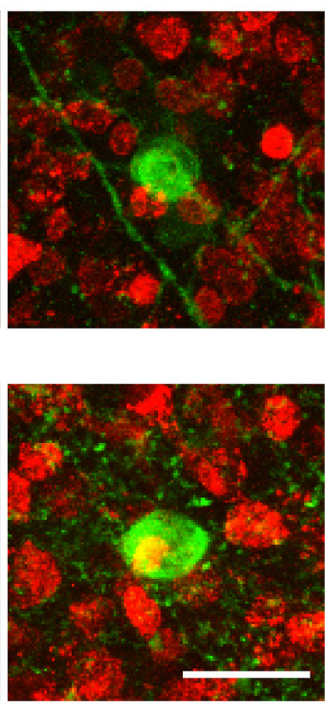

C
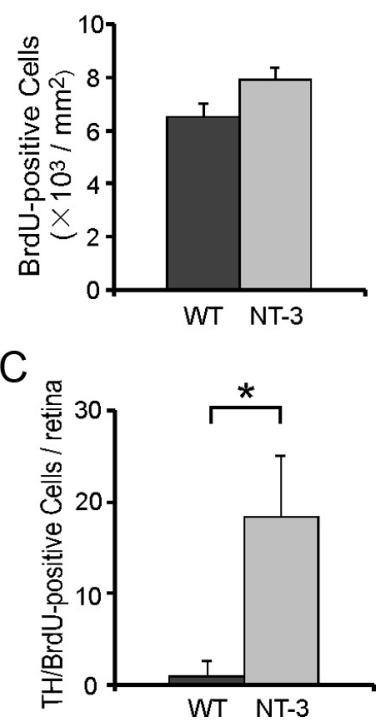

Figure 9. Mitotic cells labeled by BrdU at P4 are found to differentiate into DA cells. $\boldsymbol{A}$, Double immunolabeling of TH (green) and BrdU (red) in WT and NT-3 OE retinas at P16. Zoomed-in images (right panel) show clearly colabeled TH plus BrdU cells in the NT-3 OE, but not in the WT retinas. The arrows point to more double-labeled TH cells in the NT-3 OE retina. Scale bar, $20 \mu \mathrm{m}$. $B$, The number of BrdU-positive cells in the inner INL where TH cell bodies were found slightly increased but there was no significant difference. $\boldsymbol{C}$, A lot more of TH cells were found to be colabeled with BrdU in NT-3 OE than WT retinas. Error bar represents standard error of the mean.

0.24, Student's $t$ test; Fig. 10C). Very few cells were doublelabeled by BrdU and calretinin antibodies in the WT retinas $(2.0 \pm 0.8 ; n=3$ retinas; Fig. $10 B, E)$. Comparable colabeling of $\mathrm{BrdU}$ and calretinin was found in NT-3 OE retinas $(1.8 \pm 0.5$; $n=3$ retinas; $p=0.62$; Fig. $10 B, E)$. We further counted calretinin-positive cells in the INL and in the GCL separately at P30 and found no difference between WT and NT-3 OE retinas (Fig. $10 F, G$ ). The mean density of calretinin cells in the INL was $1948 \pm 48 / \mathrm{mm}^{2}$ in NT-3 OE retinas, which was similar to that in WT (2068 \pm 46 cells $/ \mathrm{mm}^{2} ; p=0.08$ in Student's $t$ test). Similar findings applied in the GCL (NT-3 OE, $2328 \pm 77$ cells $/ \mathrm{mm}^{2}$; WT, $2388 \pm 99$ cells $/ \mathrm{mm}^{2} ; p=0.64$; Fig. 10G). Our data reveal that the additional mitotic cells found at $\mathrm{P} 4$ are not calretininpositive amacrine or RGCs in NT-3 OE retinas.

We also examined whether the increase of mitosis at P4 upregulated rod ON bipolar cell differentiation in NT-3 OE retinas (Fig. $10 A, D, H, I$ ). In the WT retinas, a large proportion of BrdUcells were colabeled by $\mathrm{PKC} \alpha$, a marker for rod ON bipolar cells, at P16 (9.8 $\pm 1.7 ; n=3$ retinas; Fig. $10 A, D)$, confirming the postnatal birth of rod ON bipolar cells (Young, 1985). However, no difference was found between WT and NT-3 OE retinas $(10.0 \pm 2.2 ; n=3$ retinas; $p=0.85$, Student's $t$ test; Fig. $10 A, D)$. Furthermore, no difference was found in rod ON bipolar cell number between WT and NT-3 OE retinas at P30 (WT: $30.1 \pm$ 2.3, $n=4$ retinas; NT-3 OE: $30.4 \pm 3.5, n=4$; $p=0.82$; Fig. $10 H, I)$, suggesting that rod $\mathrm{ON}$ bipolar cell differentiation was not affected in NT-3 OE retinas. Together, our data indicate that the increase in mitosis at P4 leads to more DA cells and is not generalized to other types of retinal neuron in the NT-3 OE retinas.

\section{Discussion}

In this study, we find that overexpression of NT-3 leads to an increase of DA cell density and a comparable change in DA cell dendrites in the retina. We further investigate whether NT-3 upregulates DA cell density by promoting neuron differentiation into DA cells or by decreasing retinal cell death during develop- ment. We find that overexpression of NT-3 does not affect overall cell apoptosis in the first two postnatal weeks. In contrast, while overexpression of NT-3 does not affect cell mitosis at E13.5E15.5, it promotes mitosis at P4. More DA cells are thus observed in NT-3 OE mice at and after P4. Moreover, we confirm that the additional mitotic cells found at $\mathrm{P} 4$ in NT-3 OE retinas indeed differentiate into DA cells. These results suggest that NT-3 regulates the development of DA cells by promoting cell mitosis after birth.

\section{Neurotrophin signaling in retinal development}

In the retina, neurotrophins and their Trk receptors are expressed both prenatally and postnatally (Hallbook et al., 1996; Llamosas et al., 1997; Bennett et al., 1999; Nakazawa et al., 2002; Seki et al., 2004; Liu et al., 2007, 2009). TrkC, the highaffinity receptor for NT-3, is first detectable at E14 and becomes evident in the INL at P4 and P7 (Nakazawa et al., 2002). During postnatal development, TrkC gradually increases with age (Nakazawa et al., 2002) and NT-3 maintains constant expression level (Liu et al., 2009).

The general signaling mechanisms of neurotrophins have been well documented (Huang and Reichardt, 2001). It is shown that NT-3 could activate different Trk receptors under different circumstances. For example, NT-3 is required for activation of TrkB during neurogenesis and TrkA during target tissue innervation in dorsal root ganglia (Fariñas et al., 1998; Coppola et al., 2001). In retina, NT-3 signaling promotes the conversion of neuroepithelial cells into neurons (Frade et al., 1999; Das et al., 2000). Perturbing NT-3-TrkC signaling results in a reduction of all cell types (Das et al., 2000). However, NT-3 may bind to the lowaffinity receptor P75NTR to activate the prodeath pathway (for review, see Hackam, 2008).

In DA cells, NT-3 and TrkB are detected (Cellerino and Kohler, 1997; Liu et al., 2009), and TrkC is only shown in the INL (most likely in amacrine cells) (Nag and Wadhwa, 1999; Nakazawa et al., 2002). Little is known whether the expression 

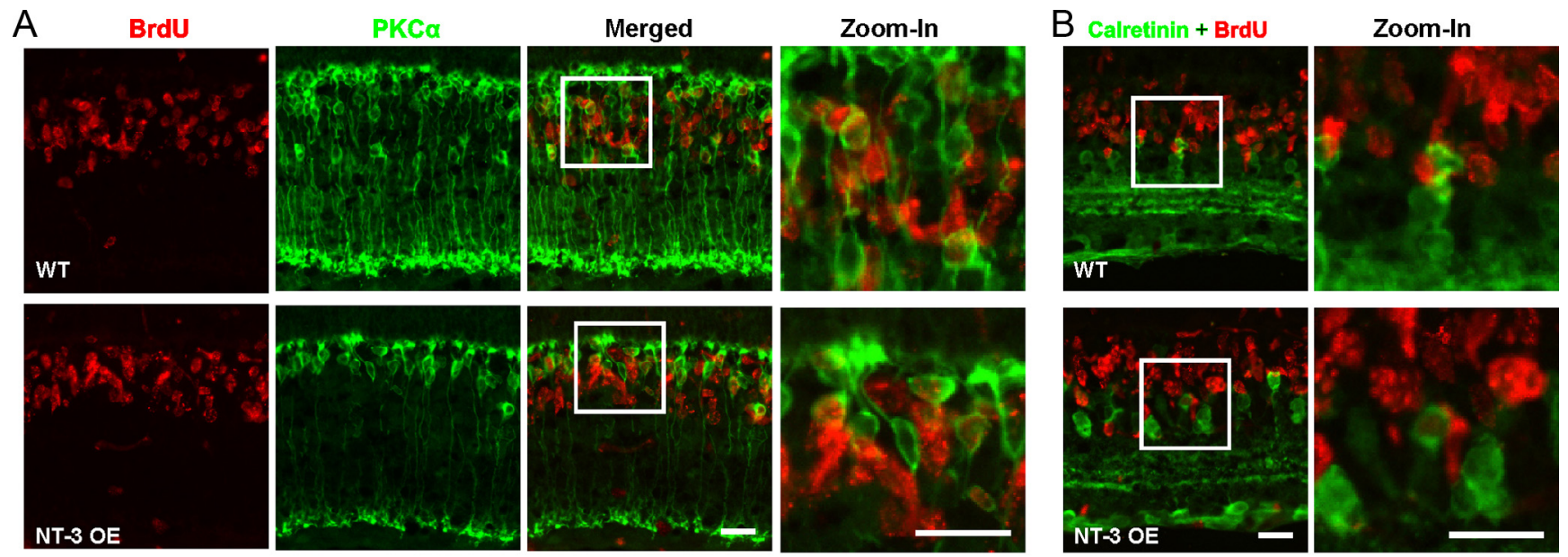

C

D
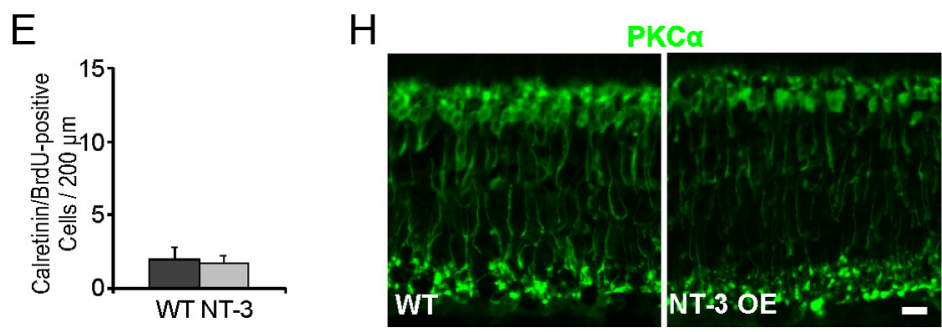

F
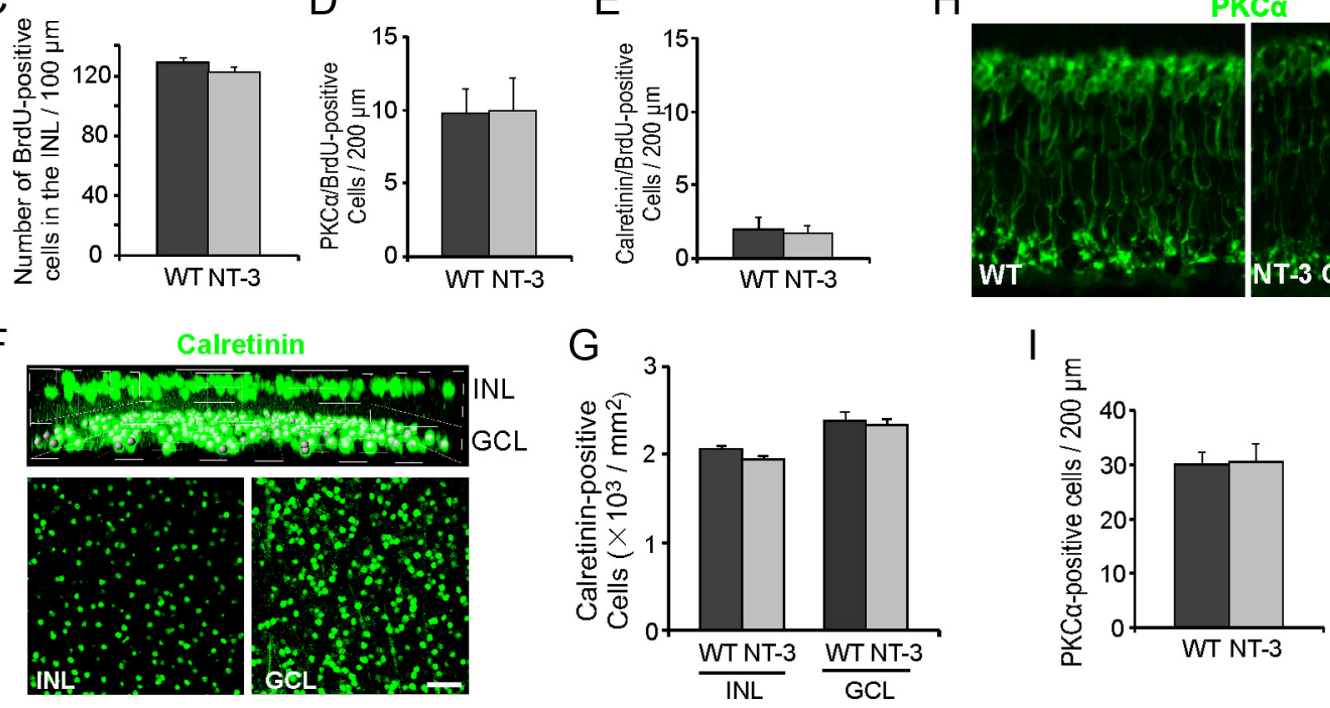

Figure 10. The differentiation of rod ON bipolar or calretinin-amacrine cells and their final numbers are not affected in NT-3 OE retinas. $\boldsymbol{A}, \boldsymbol{B}$, Double immunolabeling of PKC $\alpha(\boldsymbol{A})$ and calretinin ( $\boldsymbol{B}$; green) with BrdU (red) in WT and NT-3 OE retinas at P16. BrdU was found to colabel many bipolar cells, but not calretinin-positive cells. Scale bar, $20 \mu \mathrm{m}$. C, Compared with WT, the numbers of BrdU-positive cells in the INL did not change in NT-3 OE retinal sections. $\boldsymbol{D}, \boldsymbol{E}$, Quantifications of colabeled BrdU cells with PKC $\alpha(\boldsymbol{D})$ and calretinin $(\boldsymbol{E})$ show no difference between WT and NT-3 $0 \mathrm{E}$ retinas. $\boldsymbol{F}$, Confocal images of the calretinin-positive amacrine cells in the INL and displaced amacrine cells and RGCs in the GCL in a WT retina. In the orthogonal view (top), calretinin-positive cells in the GCL were marked with gray balls. Grid size and scale bar, $50 \mu \mathrm{m}$. G, No difference was found in the number of calretinin-positive cells in the INL (left) and the GCL (right) between WT and NT-3 OE mice at P25. H, Immunolabeling of PKC $\alpha$ in WT and NT-3 OE retinal sections at P30. Scale bar, $20 \mu \mathrm{m}$. I, Quantification of the number of PKC $\alpha$-positive cells shows no difference between WT and NT-3 0 E retinas at $\mathrm{P} 30$. Error bar represents standard error of the mean.

levels of Trk receptors in DA cells are regulated the same way as in the whole retina. Even less is known whether the phosphorylation of Trk receptors is developmentally regulated in DA cells. This is partially due to the difficulties in quantifying their changes in subtype of retinal cells, especially for TrkC, which has much lower expression level than TrkA and TrkB (Nakazawa et al., 2002). Further studies are needed to investigate how NT-3 signaling specifically affects DA cell development.

\section{Differentiation of DA cells}

In mice, retinal cells are born in sequence (Young, 1985). Amacrine cells are generated mainly before birth (Young, 1985; Cepko et al., 1996), but different subtypes of amacrine cells seem to possess distinct birthdays (Voinescu et al., 2009). For example, GABAergic amacrine cells are generated 2-3 d before glycinergic amacrine cells (Voinescu et al., 2009). DA cells, which have been reported to be GABAergic in mice (Haverkamp and Wässle, 2000), are born within the GAD65/67 differential wave that peaks around E14.5 (Voinescu et al., 2009). Around 1-2\% of amacrine cells were found to be double labeled by BrdU and TH antibodies at the peak time (Voinescu et al., 2009), consistent with the fact that DA cells only constitute $\sim 1 \%$ of the total amacrine population in the INL. LaVail et al. (2008) showed that NT-3 is already overexpressed at E14.5 (Lavail et al., 2008). Interestingly, we found no significant difference in DA cell number between WT and NT-3 OE retinas before P4 (Fig. 7), suggesting that overexpression of NT-3 before birth does not affect DA cell differentiation.

After birth, most mitotic cells are born into rod cells and bipolar cells (Young, 1985). LaVail et al. (2008) showed that the thickness of the outer nuclear layer (ONL) in NT-3 OE mice was indistinguishable from that of WT (Lavail et al., 2008). Here, we find that overexpression of NT-3 does not affect the number of rod ON bipolar and calretinin-positive amacrine cells and RGCs (Fig. 10). Moreover, we confirm that mitotic cells labeled at P3-P4 are differentiated into DA cells (Fig. 9), supporting the conclusion that overexpression of NT-3 stimulates a new wave of DA cell genesis after birth. 


\section{Cell apoptosis in the retina: actions of neurotrophins}

Retinal development is accompanied by naturally occurring cell death (Young, 1984; Linden and Pinto, 1985). Different subtypes of retinal neuron in the ONL and the INL undergo different cell loss (Young, 1984; Williams et al., 1990; Linden et al., 1999). For example, compared with total cells present on the day of birth, Young (1984) estimated that $\sim 7.8 \%$ of amacrine cells, $24.5 \%$ of the cells in the INL, and $8.6 \%$ of the cells in the GCL might undergo degeneration. Different magnitudes of cell death have been estimated even for the same type of retinal neuron. Compared with the study by Young (1984), other groups suggested that the number of RGCs was reduced by $\sim 50 \%$ during development (Potts et al., 1982; Perry et al., 1983; Williams et al., 1990). It remains to be determined the exact percentage of cell death of each subtype of amacrine cells during neonatal development.

It is controversial whether neurotrophins regulate cell survival in the retina. For example, it was shown that NT- $4 / 5$ reduced cell death in the neonatal rat retina (Cui and Harvey, 2000). By contrast, other study suggested that NT-4 did not protect developing retinal neurons from apoptosis in rat retinal explants (Martins et al., 2005). BDNF controlled cell apoptosis in the chick retina (Frade et al., 1999), but the final number of survived RGCs was not affected by BDNF signaling in the mouse retina (Pollock et al., 2003). Overexpression of BDNF increased DA cell number (Liu et al., 2007); however, removal of TrkB receptor in the retina did not change DA cell number (Grishanin et al., 2008). Although we cannot rule out the possibility that the apoptosis of DA cells might be specifically altered by NT-3, the overall number of cells undergoing apoptosis in the mouse retina during postnatal development was not affected (Fig. 4).

\section{Establishment of DA cell structure and distribution}

The tiling properties of retinal neurons represents an economical coverage of two-dimensional receptive domains, which is presumably maintained by persistent repulsive interactions between neighboring cells (MacNeil and Masland, 1998). For example, the spacing properties of DA cells were modulated by selective neuronal death, which eliminated DA cells in close proximity to one another, thereby creating the exclusion zone for every DA cell (Raven et al., 2003). In this study, we show that, in NT-3 OE retinas, DA cells become more randomly distributed after more DA cells are generated (Fig. 2), implying that NT-3 may not play a direct role in regulating DA cell spacing properties. At the same time, more studies suggest that the dendritic repulsion may not be required to establish the dendritic field structure; instead, it may be an end-stage fine-tuning mechanism for more efficient coverage of the retinal surface (Lin et al., 2004; Keeley and Reese, 2010). In $\mathrm{Bax}^{-1-}$ mice, although the dendritic fields of DA cells were smaller, they did not reduce their field extent in proportion to the increase in homotypic density (Keeley and Reese, 2010). Because the DA cell density increased approximately threefold in NT-3 OE mice, the DA cell processes became threefold thicker than WT retinas (Fig. 3), supporting the idea that the morphogenesis of DA cells is independent of homotypic interactions.

The structure of DA cell processes can also be determined by internal mechanisms such as Dscam, an Ig superfamily member adhesion molecule (Fuerst et al., 2008). In Dscam ${ }^{-1-}$ retinas, DA cells had a large number of processes that self-crossed (Fuerst et al., 2008). In mice with TrkB conditionally eliminated within the retina, the complexity of neuronal processes of DA cells was reduced (Grishanin et al., 2008). Here, our study shows that overexpression of NT-3 does not affect the overall morphological characteristics of individual DA cells (Fig. 3), although we cannot rule out the possibility that there are fine changes of dendritic morphology in individual DA cells. The responsible developmental mechanisms of DA cell morphology remain to be elucidated.

In summary, we demonstrate that overexpression of NT-3 promotes mitosis of DA cells at $\mathrm{P} 4$, and this increase of mitosis after birth is not generalized throughout the retina. Given the absence of NT-3 action on apoptosis in the NT-3 OE mice, we consider that NT-3 regulates DA cell numbers most likely through promoting a new wave of cell division after birth.

\section{References}

Bennett JL, Zeiler SR, Jones KR (1999) Patterned expression of BDNF and NT-3 in the retina and anterior segment of the developing mammalian eye. Invest Ophthalmol Vis Sci 40:2996-3005.

Calamusa M, Pattabiraman PP, Pozdeyev N, Iuvone PM, Cellerino A, Domenici L (2007) Specific alterations of tyrosine hydroxylase immunopositive cells in the retina of NT-4 knock out mice. Vision Res 47:1523-1536.

Cellerino A, Kohler K (1997) Brain-derived neurotrophic factor/neurotrophin-4 receptor TrkB is localized on ganglion cells and dopaminergic amacrine cells in the vertebrate retina. J Comp Neurol 386:149-160.

Cellerino A, Pinzón-Duarte G, Carroll P, Kohler K (1998) Brain-derived neurotrophic factor modulates the development of the dopaminergic network in the rodent retina. J Neurosci 18:3351-3362.

Cepko CL, Austin CP, Yang X, Alexiades M, Ezzeddine D (1996) Cell fate determination in the vertebrate retina. Proc Natl Acad Sci USA 93:589-595.

Chen D, Pacal M, Wenzel P, Knoepfler PS, Leone G, Bremner R (2009) Division and apoptosis of E2f-deficient retinal progenitors. Nature 462:925-929.

Coppola V, Kucera J, Palko ME, Martinez-De Velasco J, Lyons WE, Fritzsch B, Tessarollo L (2001) Dissection of NT3 functions in vivo by gene replacement strategy. Development 128:4315-4327.

Cui Q, Harvey AR (2000) NT-4/5 reduces cell death in inner nuclear as well as ganglion cell layers in neonatal rat retina. Neuroreport 11:3921-3924.

Das I, Sparrow JR, Lin MI, Shih E, Mikawa T, Hempstead BL (2000) Trk C signaling is required for retinal progenitor cell proliferation. J Neurosci 20:2887-2895.

de Melo J, Zhou QP, Zhang Q, Zhang S, Fonseca M, Wigle JT, Eisenstat DD (2008) Dlx2 homeobox gene transcriptional regulation of Trkb neurotrophin receptor expression during mouse retinal development. Nucleic Acids Res 36:872-884.

Evans JA, Battelle BA (1987) Histogenesis of dopamine-containing neurons in the rat retina. Exp Eye Res 44:407-414.

Fariñas I, Wilkinson GA, Backus C, Reichardt LF, Patapoutian A (1998) Characterization of neurotrophin and Trk receptor functions in developing sensory ganglia: direct NT-3 activation of TrkB neurons in vivo. Neuron 21:325-334.

Feng L, Xie X, Joshi PS, Yang Z, Shibasaki K, Chow RL, Gan L (2006) Requirement for Bhlhb5 in the specification of amacrine and cone bipolar subtypes in mouse retina. Development 133:4815-4825.

Frade JM, Bovolenta P, Rodríguez-Tébar A (1999) Neurotrophins and other growth factors in the generation of retinal neurons. Microsc Res Tech 45:243-251.

Fuerst PG, Koizumi A, Masland RH, Burgess RW (2008) Neurite arborization and mosaic spacing in the mouse retina require DSCAM. Nature 451:470-474.

Grishanin RN, Yang H, Liu X, Donohue-Rolfe K, Nune GC, Zang K, Xu B, Duncan JL, Lavail MM, Copenhagen DR, Reichardt LF (2008) Retinal TrkB receptors regulate neural development in the inner, but not outer, retina. Mol Cell Neurosci 38:431-443.

Hackam AS (2008) Regulation of neurotrophin expression and activity in the retina. Adv Exp Med Biol 613:343-349.

Hallbook F, Backstrom A, Kullander K, Ebendal T, Carri NG (1996) Expression of neurotrophins and trk receptors in the avian retina. J Comp Neurol 364:664-676.

Hatakeyama J, Kageyama R (2002) Retrovirus-mediated gene transfer to retinal explants. Methods 28:387-395.

Haverkamp S, Wässle S (2000) Immunocytochemical analysis of the mouse retina. J Comp Neurol 424:1-23.

Huang EJ, Reichardt LF (2001) Neurotrophins: roles in neuronal development and function. Annu Rev Neurosci 24:677-736. 
Keeley PW, Reese BE (2010) Morphology of dopaminergic amacrine cells in the mouse retina: independence from homotypic interactions. J Comp Neurol 518:1220-1231.

Landi S, Ciucci F, Maffei L, Berardi N, Cenni MC (2009) Setting the pace for retinal development: environmental enrichment acts through insulin-like growth factor 1 and brain-derived neurotrophic factor. J Neurosci 29:10809-10819.

Lavail MM, Nishikawa S, Duncan JL, Yang H, Matthes MT, Yasumura D, Vollrath D, Overbeek PA, Ash JD, Robinson ML (2008) Sustained delivery of NT-3 from lens fiber cells in transgenic mice reveals specificity of neuroprotection in retinal degenerations. J Comp Neurol 511:724-735.

Lin B, Wang SW, Masland RH (2004) Retinal ganglion cell type, size, and spacing can be specified independent of homotypic dendritic contacts. Neuron 43:475-485.

Linden R, Pinto LH (1985) Developmental genetics of the retina: evidence that the pearl mutation in the mouse affects the time course of natural cell death in the ganglion cell layer. Exp Brain Res 60:79-86.

Linden R, Rehen SK, Chiarini LB (1999) Apoptosis in developing retinal tissue. Prog Retin Eye Res 18:133-165.

Liu X, Grishanin RN, Tolwani RJ, Rentería RC, Xu B, Reichardt LF, Copenhagen DR (2007) Brain-derived neurotrophic factor and TrkB modulate visual experience-dependent refinement of neuronal pathways in retina. J Neurosci 27:7256-7267.

Liu X, Robinson ML, Schreiber AM, Wu V, Lavail MM, Cang J, Copenhagen DR (2009) Regulation of neonatal development of retinal ganglion cell dendrites by neurotrophin-3 overexpression. J Comp Neurol 514:449-458.

Liu Y, Encinas M, Comella JX, Aldea M, Gallego C (2004) Basic helix-loophelix proteins bind to TrkB and p21(Cip1) promoters linking differentiation and cell cycle arrest in neuroblastoma cells. Mol Cell Biol 24:26622672.

Llamosas MM, Cernuda-Cernuda R, Huerta JJ, Vega JA, García-Fernández JM (1997) Neurotrophin receptors expression in the developing mouse retina: an immunohistochemical study. Anat Embryol (Berl) 195:337-344.

MacNeil MA, Masland RH (1998) Extreme diversity among amacrine cells: implications for function. Neuron 20:971-982.

Martins RA, Silveira MS, Curado MR, Police AI, Linden R (2005) NMDA receptor activation modulates programmed cell death during early postnatal retinal development: a BDNF-dependent mechanism. J Neurochem 95:244-253

Masland RH, Rizzo JF 3rd, Sandell JH (1993) Developmental variation in the structure of the retina. J Neurosci 13:5194-5202.

Nag TC, Wadhwa S (1999) Neurotrophin receptors (Trk A, Trk B, and Trk C) in the developing and adult human retina. Brain Res 117:179-189.

Nakazawa T, Nakano I, Sato M, Nakamura T, Tamai M, Mori N (2002) Comparative expression profiles of Trk receptors and Shc-related phos- photyrosine adapters during retinal development: potential roles of $\mathrm{N}$ $\mathrm{Shc} / \mathrm{ShcC}$ in brain-derived neurotrophic factor signal transduction and modulation. J Neurosci Res 68:668-680.

Nguyen-Legros J, Vigny A, Gay M (1983) Post-natal development of THlike immunoreactivity in the rat retina. Exp Eye Res 37:23-32.

Pan L, Yang Z, Feng L, Gan L (2005) Functional equivalence of Brn3 POUdomain transcription factors in mouse retinal neurogenesis. Development 132:703-712.

Perry VH, Henderson Z, Linden R (1983) Postnatal changes in retinal ganglion cell and optic axon populations in the pigmented rat. J Comp Neurol 219:356-368.

Pollock GS, Robichon R, Boyd KA, Kerkel KA, Kramer M, Lyles J, Ambalavanar R, Khan A, Kaplan DR, Williams RW, Frost DO (2003) TrkB receptor signaling regulates developmental death dynamics, but not final number, of retinal ganglion cells. J Neurosci 23:10137-10145.

Potts RA, Dreher B, Bennett MR (1982) The loss of ganglion cells in the developing retina of the rat. Brain Res 255:481-486.

Raven MA, Eglen SJ, Ohab JJ, Reese BE (2003) Determinants of the exclusion zone in dopaminergic amacrine cell mosaics. J Comp Neurol 461:123-136.

Robinson ML, Overbeek PA, Verran DJ, Grizzle WE, Stockard CR, Friesel R, Maciag T, Thompson JA (1995) Extracellular FGF-1 acts as a lens differentiation factor in transgenic mice. Development 121:505-514.

Seki M, Fukuchi T, Tanaka T, Nawa H, Takei N, Abe H (2004) Quantitative analyses of mRNA and protein levels of neurotrophin-3 in the rat retina during postnatal development and aging. Jpn J Ophthalmol 48:460-464.

Sennlaub F, Courtois Y, Goureau O (2002) Inducible nitric oxide synthase mediates retinal apoptosis in ischemic proliferative retinopathy. J Neurosci 22:3987-3993.

Sharma RK (2001) Development and survival of tyrosine hydroxylase containing neurons in RCS rat retinae. Curr Eye Res 23:256-262.

Voinescu PE, Emanuela P, Kay JN, Sanes JR (2009) Birthdays of retinal amacrine cell subtypes are systematically related to their molecular identity and soma position. J Comp Neurol 517:737-750.

Whitney IE, Raven MA, Ciobanu DC, Williams RW, Reese BE (2009) Multiple genes on chromosome 7 regulate dopaminergic amacrine cell number in the mouse retina. Invest Ophthalmol Vis Sci 50:1996-2003.

Williams MA, Piñon LG, Linden R, Pinto LH (1990) The pearl mutation accelerates the schedule of natural cell death in the early postnatal retina. Exp Brain Res 82:393-400.

Witkovsky P (2004) Dopamine and retinal function. Doc Ophthalmol 108:17-40.

Young RW (1984) Cell death during differentiation of the retina in the mouse. J Comp Neurol 229:362-373.

Young RW (1985) Cell differentiation in the retina of the mouse. Anat Rec 212:199-205. 